\title{
Transient pseudohypoaldosteronism
}

INSERM

\section{Source}

INSERM. (1999). Orphanet: an online rare disease and orphan drug data base. Transient pseudohypoaldosteronism. ORPHA:93164

Transient pseudohypoaldosteronism is a renal tubulopathy characterized by renal tubular resistance to aldosterone, characterized by hyponatremia, metabolic acidosis and hyperkalemia and manifesting as dehydration, secondary to urinary tract malformation and infections in infants. 